\title{
Effects of the physical and chemical properties of petroleum coke on its slurryability
}

\author{
Gao Fuyan ${ }^{1,2}$, Liu Jianzhong ${ }^{1 *}$, Wang Chuancheng ${ }^{1}$, Zhou Junhu' ${ }^{1}$ and \\ Cen Kefa ${ }^{1}$
}

${ }^{1}$ State Key Laboratory of Clean Energy Utilization, Zhejiang University, Hangzhou, Zhejiang 310027, China

${ }^{2}$ Ningbo Institute of Technology, Zhejiang University, Ningbo, Zhejiang 315100, China

(C) China University of Petroleum (Beijing) and Springer-Verlag Berlin Heidelberg 2012

\begin{abstract}
In this study, the effects of particle size distribution (PSD), chemical composition and pore structure of petroleum coke on the slurryability of petroleum coke water slurry (PCWS) were investigated. Four petroleum cokes were studied, and they showed completely different slurryability. The solid concentration at fixed viscosity (i.e. apparent viscosity of $1000 \mathrm{mPa}$ ) (SCFV) of four PCWSs is different from each other, with the highest value of $70.9 \%$, and lowest of $62.1 \%$. The apparent viscosity of the four PCWSs all increased with an increase of the solid concentration. The results showed that the PSD, inherent moisture content, specific surface area and pore volume of petroleum coke were key factors to affect the slurryability. The slurryability was enhanced with increasing PSD range and particle packing fraction, and with decreasing inherent moisture content, specific surface area and pore volume.
\end{abstract}

Key words: Petroleum coke, petroleum coke water slurry, slurryability, particle size distribution, pore structure

\section{Introduction}

Petroleum coke, an end product of the petroleum refining process, can be used as a fuel due to its high calorific value (Sheng et al, 2007). Over the past two decades, with the decrease of high quality fuel and the increase of the output of petroleum coke, the petroleum coke has caught increasing attention as a substitute fuel. In the 1960s and 1970s, people began to study petroleum coke characteristics such as combustion, pollutants emission and agglomeration. Since the middle of the 1980s, many circulating fluidized bed (CFB) boilers, for petroleum coke as fuel, were designed and set up in succession. Nowadays CFB boilers play an important role in burning petroleum coke, but there are unsolved problems, such as high carbon content in fly ash, boiler abrasion and solid agglomerations (Chen and $\mathrm{Lu}, 2007$; Iribarne et al, 2003).

With the development of coal water slurry (CWS) technology, increasing attention has been paid to petroleum coke water slurry (PCWS), because it is a good way for clean, efficient utilization of petroleum coke. PCWS is a new-style liquid fuel and has similar flow characteristics to oil. So PCWS is considered as a substitute for oil or a gaseous fuel (Zou et al, 2008). At present, the investigation of PCWS is mainly focused on its ignition and combustion characteristics. Zhao et al (2008a; 2008b) studied the ignition and combustion characteristics of PCWS by

*Corresponding author. email address: jzliu@zju.edu.cn

Received July 4, 2011 using thermogravimetric apparatus, and compared the combustibility of PCWS with that of CWS, giving the combustion reaction kinetics characteristics of PCWS. Yang et al (2008) investigated the slurryability of lignite and its mixture with different proportions of petroleum coke, and found that the complementarity of lignite and petroleum coke plays the key role in getting high mass fraction of cokelignite-water slurries.

It has been found that the slurryability of CWS is greatly affected by the physical and chemical properties of coals, such as particle size distribution (PSD), chemical compositions (viz. moisture, ash, volatile, oxygen, carbon, function group, etc), surface characteristics (viz. wettability, adsorption, Zeta potential, etc) and pore structures (Boylu et al, 2004; Cheng et al, 2008; Qiu et al, 2007; Zhou et al, 2008). However, the research on PCWS is rarely reported. In this paper, the effects of the physical and chemical properties of petroleum coke on the slurryability of PCWS are studied.

\section{Material and methods}

\subsection{Material}

Four Chinese petroleum cokes, labeled as JA, JB, JC and JD, were used in experiments. JA and JB were from Qilu Petrochemical Co. Ltd. JC and JD were from Huizhou Petrochemical Co. Ltd. and Yanshan Petrochemical Co. Ltd. respectively. The petroleum coke was separately ground for 6 $\mathrm{h}$ in a ball mill to obtain pulverized samples. The proximate and ultimate analysis results of petroleum coke samples are shown in Table 1. 
Table 1 Proximate and ultimate analysis results of petroleum cokes

\begin{tabular}{|c|c|c|c|c|c|c|c|c|c|c|}
\hline \multirow{2}{*}{$\begin{array}{l}\text { Petroleum } \\
\text { cokes }\end{array}$} & \multicolumn{4}{|c|}{ Proximate analysis, wt $\%$} & \multirow{2}{*}{$\underset{\mathrm{kJ} \cdot \mathrm{kg}^{-1}}{Q_{\mathrm{bad}}}$} & \multicolumn{5}{|c|}{ Ultimate analysis, wt $\%$} \\
\hline & $\mathrm{M}_{\mathrm{ad}}$ & $\mathrm{A}_{\mathrm{ad}}$ & $\mathrm{V}_{\mathrm{ad}}$ & $\mathrm{FC}_{\mathrm{ad}}$ & & $\mathrm{C}_{\mathrm{ad}}$ & $\mathrm{H}_{\mathrm{ad}}$ & $\mathrm{N}_{\mathrm{ad}}$ & $\mathrm{S}_{\mathrm{t}, \mathrm{ad}}$ & $\mathrm{O}_{\mathrm{ad}}$ \\
\hline JA & 2.20 & 0.93 & 9.96 & 86.91 & 34764 & 84.76 & 3.91 & 1.62 & 5.04 & 1.54 \\
\hline JB & 1.48 & 0.52 & 11.18 & 86.82 & 35603 & 88.00 & 4.05 & 1.58 & 2.22 & 2.15 \\
\hline $\mathrm{JC}$ & 1.49 & 2.21 & 9.59 & 86.71 & 35180 & 88.38 & 3.18 & 0.90 & 0.49 & 3.35 \\
\hline JD & 1.10 & 0.32 & 8.57 & 90.01 & 36326 & 91.96 & 3.81 & 1.39 & 0.82 & 0.60 \\
\hline
\end{tabular}

Notes: Subscript ad stands for air-dried basis; M, A, V and FC stand for moisture, ash, volatile and fixed carbon, respectively; $Q_{\mathrm{b}, \mathrm{ad}}$ stands for the high heating value in air dried basis; $\mathrm{C}, \mathrm{H}, \mathrm{N}, \mathrm{S}_{\mathrm{t}}, \mathrm{O}$ stands for carbon, hydrogen, nitrogen, total sulfur, and oxygen, respectively. The oxygen data are obtained by calculation.

\subsection{Methods}

The PSDs of the pulverized petroleum coke samples were measured with a Malvern Mastersizer 2000 laser particle size analyzer (UK). The specific surface area, pore volume and pore diameter of the samples were determined using an Autosorb-1-C $\mathrm{N}_{2}$ adsorption porometer (Quantachrome instruments, USA), by the BET method.

The PCWS was prepared from $60 \mathrm{wt} \%$ pulverized petroleum coke. The chemical additive was sodium lignosulfonate with a proportion of $0.8 \mathrm{wt} \%$ of the air-dried pulverized petroleum coke. The pulverized petroleum coke, deionized water and chemical additive were mixed with an electric mixer at $1000 \mathrm{r} / \mathrm{min}$ for $10 \mathrm{~min}$ forming a PCWS. Each petroleum coke sample was used to prepare five PCWS samples with different solid concentrations.

The apparent viscosity and rheological properties of PCWS was measured on a rotary viscometer (Haake VT550, Thermo, Germany) with a MV-1 sensor. A slurry sample was first loaded into the viscometer, and then the shear rate increased from $10 \mathrm{~s}^{-1}$ to $100 \mathrm{~s}^{-1}$. Keeping shearing at $100 \mathrm{~s}^{-1}$ for $5 \mathrm{~min}$, the apparent viscosity data were recorded every $30 \mathrm{~s}$ during the 5 -minute period. Then the average apparent viscosity at $100 \mathrm{~s}^{-1}$ was calculated from the ten apparent viscosity values recorded. In the whole process, temperature was controlled at $20 \pm 1{ }^{\circ} \mathrm{C}$. The solid concentration of PCWS was determined by drying PCWS in an oven at $105^{\circ} \mathrm{C}$ for $2 \mathrm{~h}$.

Solid concentration at the fixed viscosity (i.e. apparent viscosity of $1000 \mathrm{mPa} \cdot \mathrm{s}$ ) (SCFV) is used to evaluate the slurryability of petroleum coke, the higher the SCFV of PCWS, the better the slurryability of petroleum coke (Hu et al, 2009).

\section{Results and discussion}

\subsection{Slurryability of petroleum cokes}

Fig. 1 shows the relationship between the solid concentration and apparent viscosity for the four PCWSs prepared with JA, JB, JC and JD.

It can be seen from Fig. 1 that the apparent viscosity increased with increasing solid concentration of slurries for all the four PCWSs. The reason may be that with increasing solid concentration, the solid particles content in the slurry system increased and the content of free water acting as the

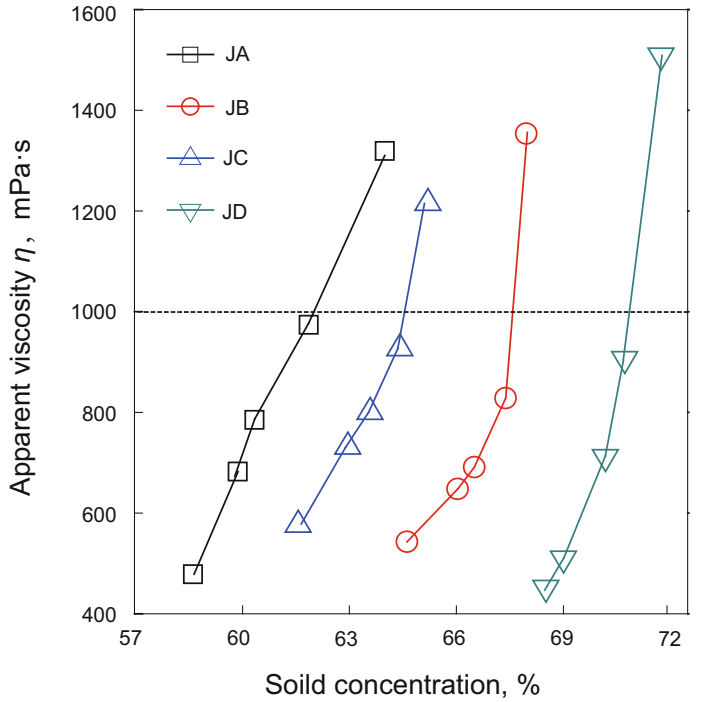

Fig. 1 The apparent viscosity as a function of solid concentration of PCWS

lubricant decreased, both resulting in increasing interparticle friction.

Table 2 shows the SCFV of PCWS. It can be seen that the four petroleum cokes have different SCFVs, from the highest value $(70.9 \%)$ of JD to the lowest value $(62.1 \%)$ of JA, indicating that the slurryability of JD is much better than that of JA. The great difference of slurryability was resulted from their different physical and chemical properties of petroleum cokes.

Table 2 SCFV of the four PCWSs

\begin{tabular}{ccccc}
\hline Petroleum cokes & JA & JB & JC & JD \\
\hline SCFV, wt $\%$ & 62.1 & 67.7 & 64.5 & 70.9 \\
\hline
\end{tabular}

\subsection{Effect of PSD on slurryability}

Particle size distribution (PSD) is the most important physical characteristic of solids, and PSD is one of the key factors for preparing high solid concentration slurry. The packing fraction of particles is directly determined by PSD, the higher the packing fraction, the higher the solid concentration (Boylu et al, 2004). Therefore, a suitable PSD, which can enable the particle system to achieve the maximum packing fraction, is desired to prepare high solid concentration slurries. 
Many models have been proposed for describing PSD ( $\mathrm{Li}$, 2007). The Rosin-Rammler (RR) distribution function is the most commonly used equation for PSD analysis (Macías et al, 2004). This function can cover the entire range of particle sizes and shows great accuracy and advantage in most cases (Allaire and Parent, 2003).

The RR distribution function has been used to describe the PSD of various types and sizes of powders. It is especially suitable for powders made by grinding, milling, and crushing processes (González et al, 2008). The general expression of the RR model is:

$$
F(d)=1-\exp \left[-\left(d / d_{\mathrm{m}}\right)^{n}\right]
$$

where $F(d)$ is the distribution function; $d$ is the particle size, $\mu \mathrm{m} ; d_{\mathrm{m}}$ is the mean particle size, $\mu \mathrm{m} ; n$ is a measure of spread of particle sizes; $d_{\mathrm{m}}$ and $n$ are adjustable parameters characteristic of the distribution (Macías et al, 2004). Eq. (1) may be expressed as:

$$
\ln \{-\ln [1-F(d)]\}=n \ln d-n \ln d_{\mathrm{m}}
$$

The parameters of the RR model is often calculated via linear regression of data, namely the relationship of $-\ln [1-F(d)]\}$ versus $\ln d$, indicating the applicability of the RR distribution function to the PSD (Macías et al, 2004). Usually, a least-squares regression analysis is used to fit a line to the data points, and the slope $n$ of the straight line can be used as the parameter for goodness of fit. When the value of $n$ is between 0.6 and 0.84 , the particle system fits the RR model well and achieves the maximum packing fraction $(\mathrm{Li}$, 2007). Table 3 shows the RR model parameters of the four experimental samples.

Table 3 Model parameters of Rosin-Rammler distributions for the four petroleum cokes

\begin{tabular}{ccc}
\hline Petroleum cokes & $n$ & $d_{\mathrm{m}}, \mu \mathrm{m}$ \\
\hline JA & 1.12 & 18.12 \\
JB & 0.70 & 18.66 \\
JC & 1.08 & 18.19 \\
JD & 0.76 & 25.46 \\
\hline
\end{tabular}

Table 3 shows that the values of model parameter $n$ for JB and JD are 0.70 and 0.76 respectively, which are between 0.6 and 0.84 ; while for JA and JC, parameter $n$ is out of this optimal range, indicating that the packing fractions of JB and JD are higher than that of JA and JC. This might be the reason why JB and JD have better slurryability than JA and JC. In addition, Table 3 also shows that the slurryability of petroleum coke was improved with increasing $d_{\mathrm{m}}$, indicating that increasing particle size is favorable to improving the slurryability.

The PSD curves of the four petroleum cokes are shown in Fig. 2. It can be seen that the ranges of PSD of JB and JD are wider than that of JA and JC. For a petroleum coke with a wide range of PSD, fine particles can fill the voids between coarse particles and therefore higher packing fractions can be obtained (Boylu et al, 2004). Accordingly JB and JD give higher packing fractions than JA and JC. This is accordance with the result of $\mathrm{RR}$ distribution function.

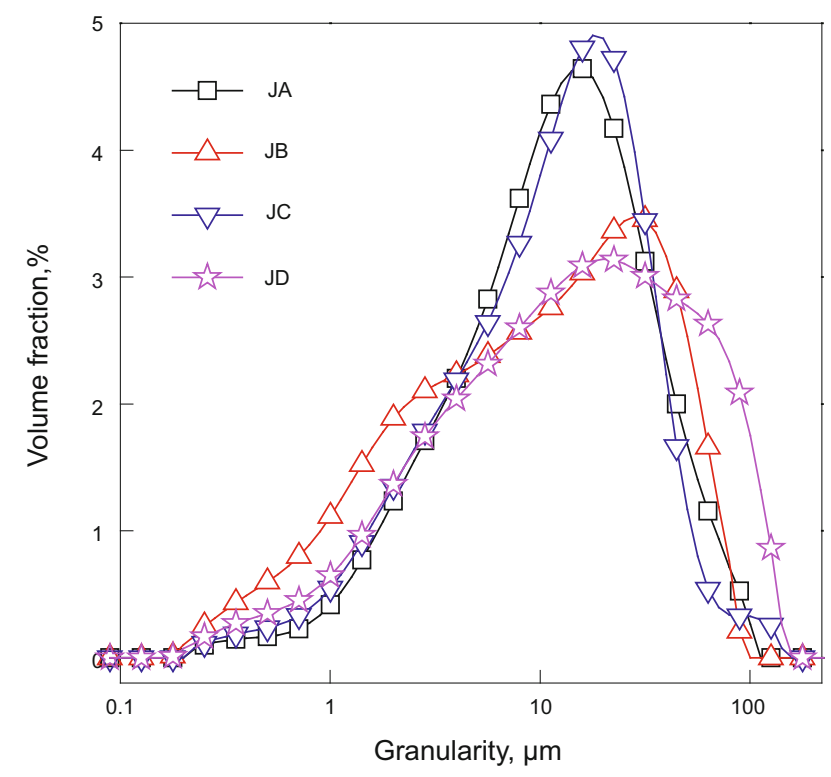

Fig. 2 PSD curves of the four petroleum cokes

\subsection{Effect of chemical compositions on slurryability}

As seen in Table 1, the four petroleum coke samples have different $\mathrm{O} / \mathrm{C}$ ratios, inherent moisture contents and ash contents. The relationship between the solid concentration (SCFV) and $\mathrm{O} / \mathrm{C}$ ratio, inherent moisture content and ash content was studied by using the multiple linear regression method, and a ternary linear regression equation was obtained using MatLab software, shown as follows:

\section{Solid concentration $(w t / w t)=0.7905-1.7475($ ash wt/wt $)$ $-0.1098(\mathrm{O} / \mathrm{C} \mathrm{wt} / \mathrm{wt})-6.8783$ (moisture wt/wt)}

Equation (3) indicates that the solid concentration of PCWS is inversely proportional to the $\mathrm{O} / \mathrm{C}$ ratio, inherent moisture content and ash content of the petroleum coke. In other words, the solid concentration of PCWS increases with decreasing $\mathrm{O} / \mathrm{C}$ ratio, inherent moisture content and ash content. The coefficient $(-6.8783)$ of the inherent moisture content is negative whose absolute value is much greater than that of the $\mathrm{O} / \mathrm{C}$ ratio $(-0.1098)$ and the ash content $(-1.7475)$, indicating that the inherent moisture content of the petroleum coke has a more adverse effect on the solid concentration of PCWS. The higher inherent moisture content, the less the free water, and leading to the higher apparent viscosities of PCWS and the worse slurryability of petroleum coke. So the inherent moisture content of petroleum coke has great influence on its slurryability. Fig. 3 shows the relationship between the inherent moisture content $\left(M_{\mathrm{ad}}\right)$ and the slurryability of petroleum cokes. As seen in Fig. 3, the lower the inherent moisture content of petroleum coke, the better the slurryability.

\subsection{Effect of pore structure on slurryability}

Petroleum coke particles have a very complicated inner 


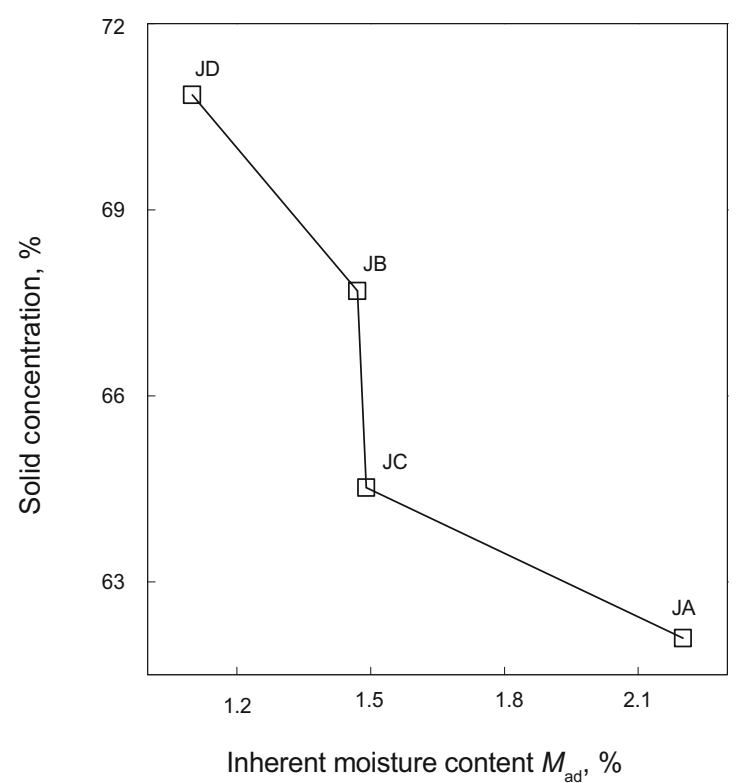

Fig. 3 Relationship of $M_{\text {ad }}$ and slurryability

pore structure which directly affects the bound water content in PCWS, and thereby influences the preparation of PCWS (Cheng et al, 2008). The effects of pore structures on the slurryability are complicated. Different pore size distributions lead to different slurryability, and completely different slurryability can also be obtained even with petroleum cokes with similar pore size distribution (Yu et al, 2006). The effect of the pore structure of the four petroleum cokes on their slurryability was studied in this work. Fig. 4 shows the pore volume distribution of the four petroleum cokes. It can be seen that they had similar pore size of around $100 \mathrm{~nm}$.

Figs. 5-7 show the slurryability versus the specific surface area, pore volume and mean pore diameter respectively. It can

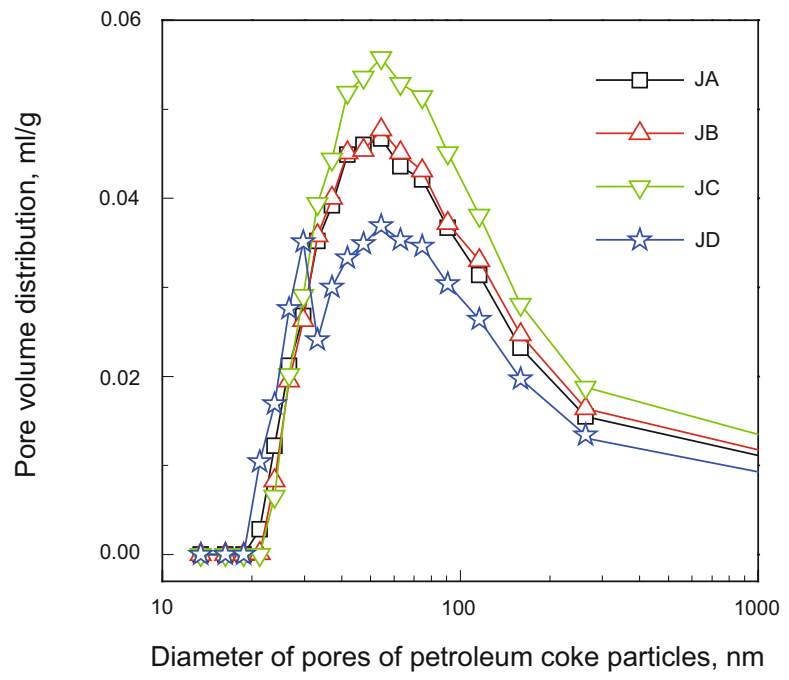

Fig. 4 Pore volume distribution of petroleum cokes be seen that the specific surface area, pore volume and mean pore diameter have good correlations with the slurryability of petroleum cokes, and that the slurryability was improved

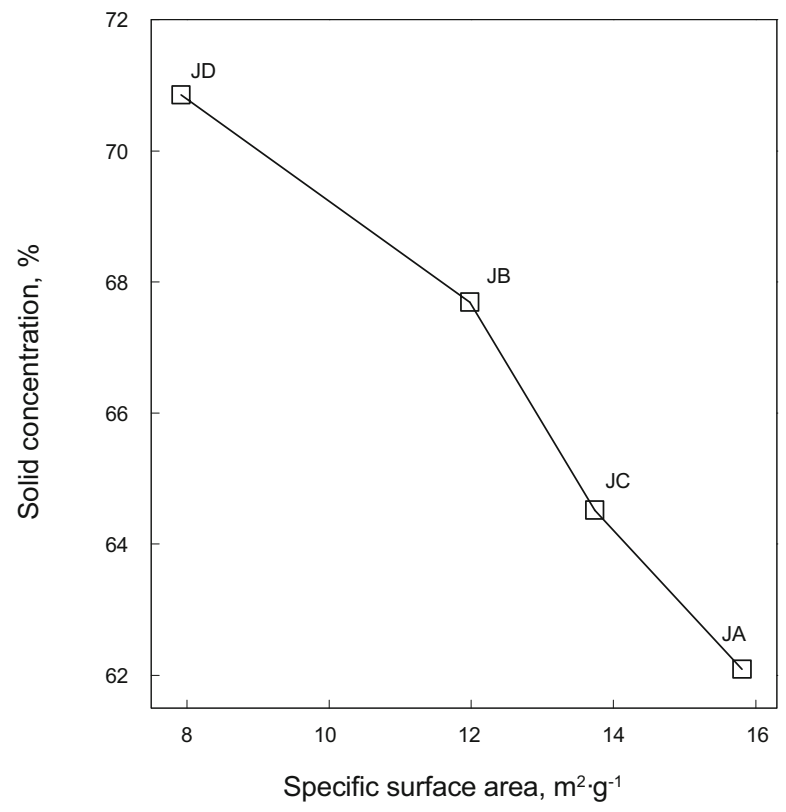

Fig. 5 Relationship of specific surface area and slurryability

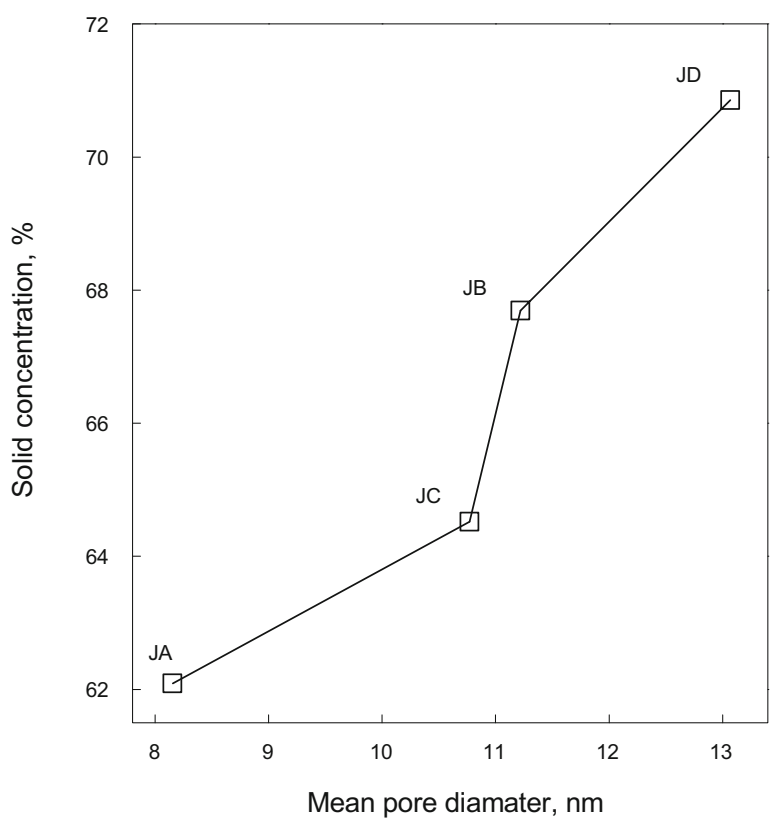

Fig. 6 Relationship of mean pore diameter and slurryability

with decreasing specific surface area and pore volume, and increasing mean pore diameter.

There are two reasons for why the slurryability can be improved with decreasing specific surface area (Kaji et al, 1986). One is that the probability of water molecules acting on the surface of petroleum coke decreases with decreasing specific surface area, resulting in a reduced water-adsorption 


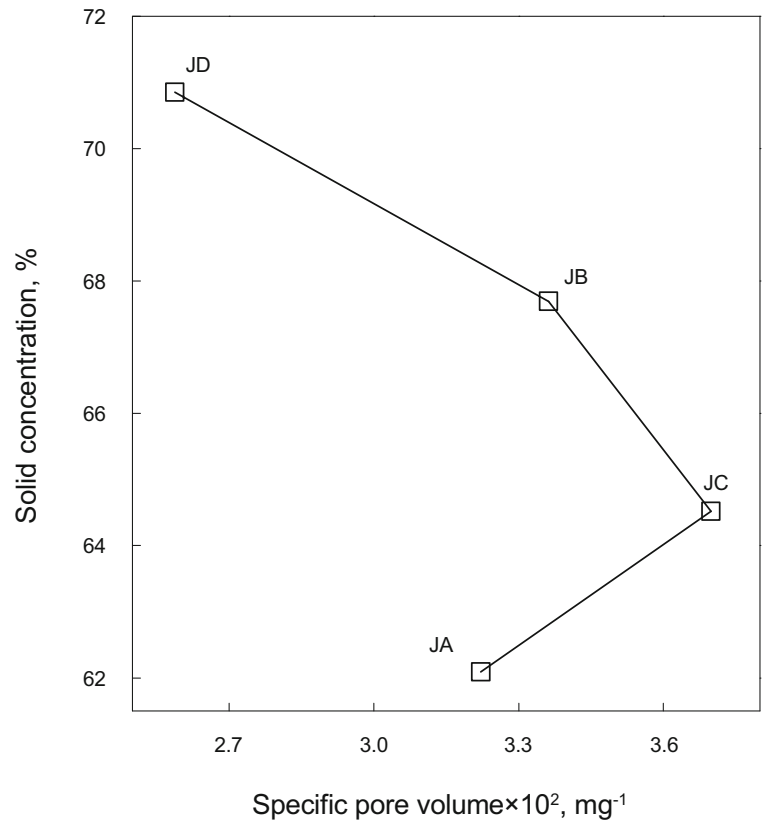

Fig. 7 Relationship of specific pore volume and slurryability

capacity of petroleum coke particles and an increased free water amount among petroleum coke particles. Another is that the probability of hydrophilic groups appearing on the surface of petroleum coke decreases with decreasing specific surface area, resulting in enhanced hydrophobic characteristics of the petroleum coke surface and reduced bound-water content in PCWS.

In addition, the slurryability was improved with decreasing specific pore volume, and the reason might be that the volume of bound water formed due to multi-layer adsorption and capillary condensation in the pores decreased with decreasing specific pore volume (Sun et al, 1996). But JA does not follow the rule, as seen in Fig. 7. This suggests that the other physical and chemical properties of JA affect its slurryability, such as the PSD, the inherent moisture content and the specific surface area. The mean pore diameter is not an independent parameter and has a definite relationship with the specific surface area and pore volume. When the mean pore diameter increases, the specific surface area or pore volume will decrease, which will be favorable to the slurryability.

\section{Conclusions}

1) Based on the results obtained in this investigation, the physical and chemical properties of petroleum coke greatly affect the slurryability. These include PSD, inherent moisture content and pore structure. Four petroleum cokes showed different SCFVs, from the highest value $(70.9 \%)$ of JD to the lowest value $(62.1 \%)$ of JA. The great difference of slurryability results from the different physical and chemical properties of the four petroleum cokes.

2) PSD is an important factor influencing the slurryability of petroleum coke. JB and ID fit the RR model well and reach or approach the maximum packing fraction, so JB and ID can obtain better slurryability; Particle-size range and mean particle size also affect the slurryability, and the slurryability improves as the particle-size range broadens or mean particle size increases.

3) The $\mathrm{O} / \mathrm{C}$ ratios, inherent moisture contents and ash contents of petroleum coke are regarded as major factors that influence the PCWS preparation. The solid concentration of PCWS is inversely proportional to the $\mathrm{O} / \mathrm{C}$ ratio, inherent moisture content and ash content of petroleum coke, and the greatest influence is the inverse effect of the inherent moisture content. The relationship between the solid concentration and $\mathrm{O} / \mathrm{C}$ ratios, inherent moisture contents and ash contents of petroleum coke was obtained by multiple linear regression method.

4) Petroleum coke particles have very complicated inner porosities, and the effects of pore structures on the slurryability of PCWS are complex. Different pore size distributions lead to different slurryability, and completely different slurryability can be obtained even if the pore size distributions are similar. For the PCWSs studied in this paper, the slurryability improves with decreasing the specific surface areas and pore volumes.

\section{Acknowledgements}

The author would like to appreciate the financial support from National Key Basic Research Program Project (No. 2010CB227001).

\section{References}

Allaire S E and Parent L E. Size guide number and Rosin-Rammler approaches to describe particle size distribution of granular organicbased fertilisers. Biosystems Engineering. 2003. 86(4): 503-509

Boylu F, Dincer H and Atesok G. Effect of coal particle size distribution, volume fraction and rank on the rheology of coal-water slurries. Fuel Processing Technology. 2004. 85(4): 241-250

Chen J H and $\mathrm{Lu} \mathrm{X} \mathrm{F.} \mathrm{Progress} \mathrm{of} \mathrm{petroleum} \mathrm{coke} \mathrm{combusting} \mathrm{in}$ circulating fluidized bed boilers-A review and future perspectives. Resources. Conservation and Recycling. 2007. 49(3): 203-216

Cheng J, Zhou J H, Li Y C, et al. Effects of pore fractal structures of ultrafine coal water slurries on rheological behaviors and combustion dynamics. Fuel. 2008. 87(12): 2620-2627

González-Tello P, Camacho F, Vicaria J M, et al. A modified NukiyamaTanasawa distribution function and a Rosin-Rammler model for the particle-size-distribution analysis. Powder Technology. 2008. 186(3): 278-281

Hu W B, He G F and Duan Q B. Study of slurrying characteristics of low-volatile coal. Coal Processing and Comprehensive Utilization. 2009. (1): 37-39 (in Chinese)

Iribarne J V, Anthony E J and Iribarne A. A scanning electron microscope study on agglomeration in petroleum coke-fired FBC boilers. Fuel Processing Technology. 2003. 82(1): 27-50

Kaji R, Muranaka Y, Otsuka K, et al. Water-absorption by coals-Effects of pore structure and surface oxygen. Fuel. 1986. 65(2): 288-291

Li Y C. Coal slurrying property's nonlinear theory and mechanism of wave energy in CWS preparing. Hangzhou: Zhejiang University. 2007. 20-23 (in Chinese)

Macías-García A, Cuerda-Correa E M and Díaz-Díez M A. Application of the Rosin-Rammler and Gates-Gaudin-Schuhmann models 
to the particle size distribution analysis of agglomerated cork Materials Characterization. 2004. 52 (2): 159-164

Qiu X Q, Zhou M S, Yang D J, et al. Evaluation of sulphonated acetoneformaldehyde (SAF) used in coal water slurries prepared from different coals. Fuel. 2007. 86(10): 1439-1445

Sheng G H, Li Q, Zhai J P, et al. Self-cementitious properties of fly ashes from $\mathrm{CFBC}$ boilers co-firing coal and high-sulphur petroleum coke. Cement and Concrete Research. 2007. 37(6): 871-876

Sun C G, Li B Q and Yu C W. Characterization of pore size distributions and slurryability of coal. Journal of Fuel Chemistry and Technology. 1996. 24(5): 434-439 (in Chinese)

Yang B L, Gong K F, Zou J H, et al. Slurryability of lignite and petroleum coke mixtures. Journal of Fuel Chemistry and Technology. 2008. 36(4): 391-396 (in Chinese)

Yu C W, Li B Q, Li W, et al. Effect of pore structure on the properties of coal water slurry. Journal of Fuel Chemistry and Technology. 2006.
34(1): 5-9 (in Chinese)

Zhao W D, Liu J Z, Zhang B S, et al. Kinetic parameters of petroleum coke water slurry combustion by different methods. Proceedings of the CSEE. 2008a. 28(17): 55-60 (in Chinese)

Zhao W D, Liu J Z, Zhou J H, et al. Combustibility of petroleum coke water slurry compared with coal water slurry. Journal of Zhejiang University (Engineering Science). 2008b. 42(10): 1795-1800 (in Chinese)

Zhou M S, Yang D J and Qiu X Q. Influence of dispersant on bound water content in coal-water slurry and its quantitative determination. Energy Conversion and Management. 2008. 49(11): 3063-3068

Zou J H, Yang B L, Gong K F, et al. Research on slurryability of petroleum coke. Chemical Engineering (China). 2008. 36(3): 22-25 (in Chinese)

(Edited by Zhu Xiuqin) 